\title{
Semantic analysis of color, light and transparency in Islamic architecture of Iran
}

Análisis semántico de color, luz y transparencia en la arquitectura islámica de Irán

Author:

Behnam Sarbakhshian ${ }^{1, *}$

SCIENTIFIC RESEARCH

How to cite this paper:

Sarbakhshian. B. Semantic analysis of color, light and transparency in Islamic architecture of Iran. North khorasan, Iran. Innovaciencia. 2019; 7 (2): 1-11. DOI:

http://dx.doi.org/10.15649/2346075X.763

Reception date:

Received: 28 February 2019

Accepted: 27 April 2019

Published: 25 October 2019

Keywords:

Islamic Architecture, Color, Light, Transparency

\section{ABSTRACT}

The subject of color, including single colors or compounds like Haft Rang (seven colors), which conveys the psychological effects and mystical interpretation of color, has a palpable presence in the realm of arts, especially in architecture. On the other hand, light as the most immaterial element of nature has always been present in Iranian architecture. In fact, it symbolizes transcendental world and spiritual realm. In traditional Iranian architecture, the conceptualization of light flourished under the influence of Islamic thought, and came to be known as the manifestation of sanctity and the spiritual world. This paper is an applied research, with an analytical approach that seeks to conduct a semantic analysis of color, light and transparency in the Islamic architecture of Iran. The data was collected using the library research. Also, some illustrations of colors and light in Islamic architecture of Iran were photographed and recorded in a field study. The analysis shows that Iranian architects have employed these factors in order to plead to the observer's sense of beauty by forging a close association between light and color in architecture. Diversity of colors, which is rooted in divine wisdom, gives an appreciation of the beauty and dimensions to human beings. Moreover, the results suggest that the Iranian architects have not been concerned with phenomenal clarity to create complexity, attractiveness, and spatial diversity, which are primarily architectural aspects, but rather have focused on cultural objectives and excellence of human beings.

Academic staff of Department of Art and Craft, Faculty of Art, University of Bojnord, North khorasan, Iran. Email: B.Sarbakhshian@ub.ac.ir 


\section{INTRODUCTION}

We inhabit in an visual age, part of which is represented by the architectural image. The symbolic form and property of light originates from the imaginative mind of humans. Light has a clear advantage over darkness. Existence is pure light and inexistence is pure darkness. When the darkness and brightness reach their maximum intensity and the penumbras are obliterated or overlooked, a positive and negative milieu is created. During the day, natural light, which forms the ostensible characteristics of the interior areas, gives it identity and personality. Light has always been one of the vital elements of human life. The heat bestowed by sunlight nurtures fertility on earth prepares the ground for revival of life. With this revitalizing phenomenon, humans can work and shape their living environment; hence, in architecture and other forms of art, light has been used in a variety of ways and shapes. In fact, humans assume a divine and sacred role for the light, perceiving it as the mediator between the world of spirit and the material world. This effect is especially evident in its decorative architectural design such as tile work in the interior and exterior of buildings where architects have displayed a preference for the application of colors that either had a reflective property or served as a symbol of light. Since color derives its identity from light and these two are inseparable, here we focus on the subject of color and its position in traditional architecture. In the following section, a more accurate analysis of color and light linkage in the buildings has been performed.

\section{Color (foundations and concepts)}

The perception of colored lighting and the ultrasonic receptions of colors in a pure state comes from an inner function of humans ${ }^{[1, \text { p. 198] }}$. The plurality of colors is far beyond the visual recognition of humans. According to studies, there are more than 170 words to express colors in Persian language ${ }_{2}$ p. 21. However, studies on color types suggest that the color spectrum covers about 7.5 million colors [3. p. 105], or even beyond that. Aristotle posited that black and white were basic colors, and the rest of colors come from distinction or blending of these two colors. Plato contended that black, white, red, and yellow were the basic colors. Islamic scholars such as Shiekh al-Rais Abu Ali Sina, Mulla Sadra and Sheikh Ishraq, among others, have elaborated on

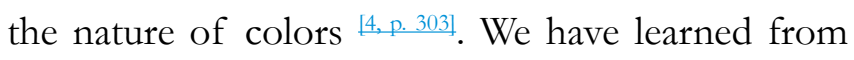
the experience that every color produces special psychological effects upon which the color concepts are founded. These effects are aggregated step by step to reach their mystical meaning. In the end, it is easy to predict that a color can acquire a mystical value by itself ${ }^{[1, \text { p. 202] }}$.

\section{A glance at color in pre-Islamic architecture}

One of the oldest historical quotes about color is attributed to Herodat's remark about Hegmataneh city, the capital of Medes, which says: "In the castle of Ekbatan (Hegmataneh or Hamedan), on which the Deioces Palace (or Dia-oku) was built, there were a total of seven fences, with the king's palace being established on the last fence, and the indentations of fences were painted with various colors: the first fence was in white, the second fence was in black, the third fringe was in purple, the fourth fence was in blue, the fifth fence was in red and orange and the sixth fence was in silver and the seventh fence was in gold “ “5, p. 90]. Elsewhere, the symbolic use of color in architecture has been discussed: "different levels of the Ziggurat from the lower to upper floors were in white (colorless hue, purity, brightness and mystery), black (a sign of the underworld and the Unseen), red (or vermilion), red-brown, the symbol of material world (the color of worldly desires, grudges and the fury of Farvardin) and blue (the symbol of sky and the vastness of inner self)". Finally, the dome or the upper ziggurat chamber was in gold, which is a symbol brilliance and lightness ${ }^{[6, p .270]}$ 


\section{COLOR IN ISLAMIC ART AND ARCHITECTURE}

The subject of color and its nature, quality and effect has always been explored by ancient scholars, mystics, poets and Iranian artists. Of course, it does not mean that others have been indifferent to this topic, but in Iran, especially the Iranian mystics, special heed has been devoted to its various aspects.

One of the oldest and primary resources that has thoroughly discussed the application of building materials and their color, particularly the use of colored stones in the Islamic building, is al-E'alagh al-Nafisa Ibn Rasta, which dates back to the third century AH [7.pp. 88 - 35]. The manifestation of color in materials and light is one of its capabilities in the subliminal and terrestrial domains, where they stand in contradiction in some cases. For instance, white in light embodies the presence of all colors, but in matters, white indicates the absence of any color. On the contrary, black is a blending of diverse colors while in light, black signifies the absence of any color. Therefore, color has retained material, spiritual, and mystical values in various ways in Islamic culture and civilization. In Sufism, the color of cloaks always conveyed a significant and specific meaning [8, pp. 175 -1611. The ancient people believed that there were seven original colors, and in some ethnical dialects, there are words to signify seven primary colors including black, white, red, green, yellow, blue and brown [3, p. 106]. The tile of seven colors emerged in the evolutionary path of tile technology. In this way, access to seven colored materials allowed merging seven colors with a single furnace placement, which produced high quality and less expensive tiles. In the past, to make a multi-colored tile, it had to be placed in a furnace after adding each color, which obviously imposed practical constraints (Figure 1).

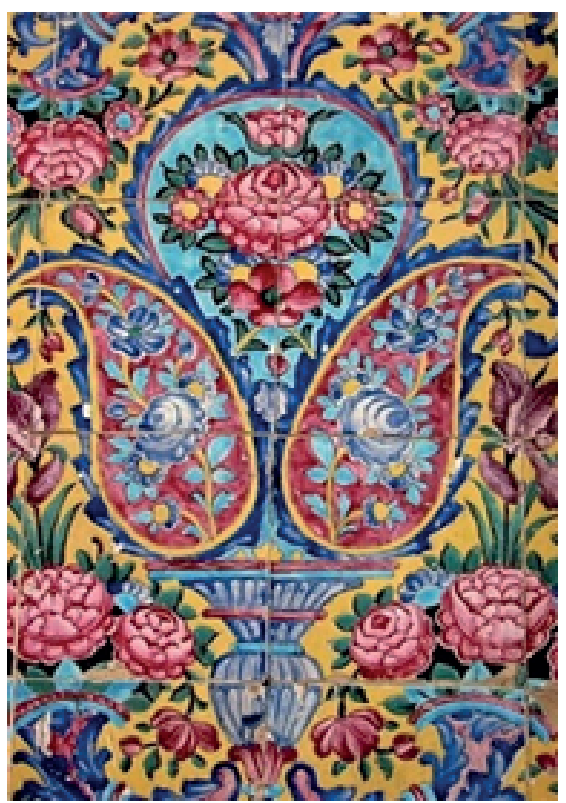

Fig.1. Example of seven-colored tiles used in traditional Iranian architecture

(www.tasnimnews.com)

Along with the application of these materials, we see the extensive utilization of colored glasses in traditional buildings, which mostly appear in old windows and sparseskylights installed in bazars and baths, or stucco decorations of buildings. Colored glass is one of the main factors in generating color schemes in Iranian buildings (Figure 2).

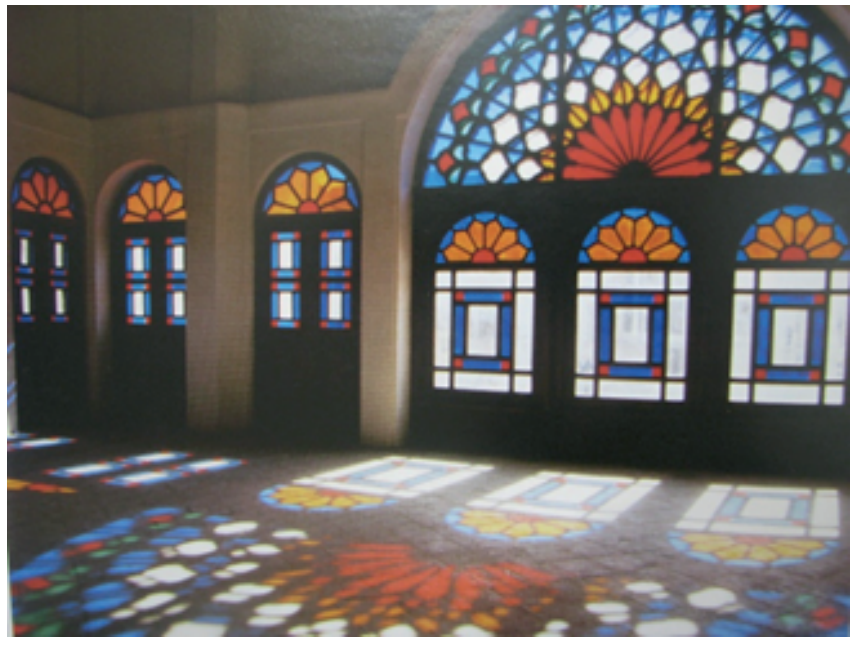

Fig. 2. A room with the central and radial role in Tabataba'i's House, Kashan, Qajar (Amraei, 2004) 
There are many evidences, especially in rich literary resources, that indicate artists, especially architects, had to be acquainted with other sciences, in particular astronomy and chromatics besides architecture, as many astronomical concepts, as well as seven-day periods, derived their meaning from seven colors.

\section{Light and Transparency}

(Meaning and Foundations)

In Dehkhoda Dictionary, light has been described as brightness, and as noted in the Quranic verse, "God is the light of Skies and the earth", it is one of the name of Allah as well.

In Moein dictionary, light has been defined as brightness, lightness, luminance and radiance. The light that is born with the dawn of the sun is one of the most magnificent phenomena in the universe that caresses the world with the touch of its beams. In fact, nothing in the world has a visual identity in the absence of light. Under normal conditions, light acts as the interface between eyes and the environment. That is, if the light is not reflected on the eyes, no image will be perceived, and thus the sense of vision loses its meaning ${ }^{[0]}$.

Transparency, on the other hand, is the motto of the 20th century architecture, with discussions of transparency mainly describing its physical aspect rather than its theoretical meanings ${ }^{[10]}$. In Persian, a variety of interpretations have been offered (e.g., what does not obstruct the penetration of light beams, such as glass, or delicate and slim materials through which you can see other things like water and glassware). In other words, in traditional architecture, glass was used to indicate the presence of light. It is tied with intrinsic and physical properties of a material that renders it objectively permeable and are more palpable and accessible. An important point in creating transparency is levels is that the ratio of transparent dimensions to its adjacent space should be significantly high before applying that term. That is, transparency is not used to describe small surface openings. Materials may be transparent, semitransparent, or opaque depending on their intrinsic properties. Materials like glass that let light directly through are transparent and more visible. On the other hand, materials such as concrete that blocks light are classified as opaque. Materials like canvas or plastics that diffuse light are considered as are semitransparent.

According to Siegfried Giedion, space, as one of the architectural constituents, played a pivotal role in the study of the architecture in the past. By dividing the historical periods into three phases, he posits that the dawn of the modern era coincides with the third stage of spatial imagination, asserting that this phase had a profound effect on architecture and urbanization. At this era, the exterior and interior space of a building are treated as equally important $\stackrel{[12]}{ }$.

Determining the nature of light is one of aspirations pursued by humans throughout history. The ancient Greeks believed that the light was composed of tiny particles that were discharged by the eye and objects were made visible after being struck by these particles. Aristotle revised this theory by claiming that light consists of very small particles emitted from bright glowing objects, and we could see objects when these particles were picked up by eyes.

In the last century, the nature of light was described by a quantum image, which segmented light energy into small and separate particles called photons. Light is the perquisite of any visual perception. It is both the appearance and manifestation. In absolute darkness, we can see neither space nor form and color; nonetheless, light is not merely a physical necessity and its psychological value is one of a major aspect of the human life in all domains. On the other hand, the concept of light is a logical concept that is taken for granted; light is inherent form and manifestation 
of the other; hence, there it is nothing brighter than light, and it is the most radiant and brilliant of things. As such, it is a coherent and unified matter, without any genus and differentia, as genus is a vague and flawed nature, which is explained from the differentia. The light is neither genus nor differentia and is therefore limitless. In other words, the definition of light is inessential as there is nothing more expressive and obvious than light by which it is defined. ${ }^{[13]}$

\section{CONCEPTS OF LIGHT AND}

\section{TRANSPARENCY}

Light implies knowledge and reason and is one of the key visual elements. Despite its immaterial and spiritual nature, it is an inalienable part of architecture, as architecture, regardless of its physical characteristics and function, can be the embodiment of an aesthetic perception.

Light is the symbol of divine wisdom and the source of all purity and goodness, and the man's departure from the darkness of ignorance to the light of knowledge has always been one of the ultimate goals of creation. On the other hand, transparency can be seen as factor that contribute to spatial integration inside and outside the building. Mirmiran posits that transparency is one of the principles governing the universe and its meaning is linked to unceasing movement and the evolution of the existence from material quality into spiritual essence. According to him, the architecture of the world is in harmony with the principle of transparency, so that in the course of the evolution of world architecture, the thickness and mass of structures have always been shrinking, which subsequently gives rise to spatial expansion inside buildings and augmented visibility. [14]. what can be gathered from this definition is that the transparency is synonymous with concepts such as seeing and visual relationship between the two spaces. On the other hand, it is difficult to summarize and categorize the semantic nuances of transparent architecture due to the wide range of interpretations offered for the concept of transparency. ${ }^{[15]}$

\section{Application of light in Iranian architecture}

The Persians from thousands of years ago (preIslamic era) have based their beliefs on the foundation of respect for light and brightness. In the pre-Islamic Iranian architecture, the manifestation of this kind of belief is palpably evident. With the advent of Islam and the revelation of the Holy Qur'an, the Iranians found concepts comparable to their beliefs in the lofty status of light and its sanctity in Surah al-Nur. "Allah is the Light of Skies and the Earth. The Iranian architecture is the truth-seeking architecture. That is, in architecture, truth is equivalent to perfection and the perfection is the quality of Allah so that every element of architecture is an inseparable part of that divine light that seeks truth. Light is a symbol of the pursuit of truth, which is spiritual and immaterial. It is presented along with other factors such as the climate and location of a building and the employment of light. Architectural configurations are built upon continuous levels of brightness. Light is one of the key determinants of space, which has a huge bearing on the transformation of spatial and physical nature of materials. The skylight radiates a special brightness that is an integral part of volumetric space. Light is always seen as a heavenly virtue, which is associated with truth and contemplation, even if the light is sometimes overshadowed by darkness. Light and shadow are essential for spatial perception, though they are never in contradiction.

"Although Iranian architecture and urbanism may seem ambiguous for foreigners, it fulfills the purpose of granting diversity to maintain vitality and identity of its inhabitants. For this reason, there are rampant diversities at micro and macro scales. The design of arches, play of light, shades and plants along with the incorporation of symbolic elements all serve a particular goal. " $[16]$. In the Iranian architecture, the 
hierarchy of light and darkness has been meticulously utilized to mark transition from one space to another. In this hierarchy, it is the intensity of light and darkness in the space that determines their significance. In the traditional pattern of traditional Iranian architecture, in houses, mosques and other public places, the special position and status of light can be tangibly felt.

For instance, consider a residential home. After setting foot in the house and halting in the hallway, the blurry and rather dark spaces, most of which are characterized with motion and pause, are driven by beams emitted from top or near top, which usher you in the courtyard as the heart and most brilliant part of the building. Along this path, the light that sneaks through apertures has been masterfully calculated. Natural light in traditional buildings always acts as a guide and enters interior space from particular directions. Today, however, light has transformed into a practical element consistent with dramatic changes in the attitude and perspective of humans. Therefore, the application of light in modern architecture has been deprived of its mysterious meaning.

\section{Light and Transparency in Iranian houses}

The place of residence represents the most important and yet the most complex space in which human needs are satisfied. From the time people lived in caves, daylight has been the harbinger of life for residents, acting as a metric to differentiate day and night for dwellers. However, as the place of residence grew more complex and artificial, light came through windows. The history of architecture can be traced back to the time when daylight infiltrated into the building through the openings of windows, conducting light, air, heat and cold in the interior of building.
In almost all religions, light is the symbol of divine wisdom and the source of all goodness and purity, and moving from darkness to light has been described as the main goal of men. "The direction of houses is a variable of the angle of sunshine and the Qibla. Every façade of the building was designed to accommodate a specific season of the year, and elements such as hall, windtower, Panjdari, Sedari and sash window were some of solutions (Figures 3 and 4).

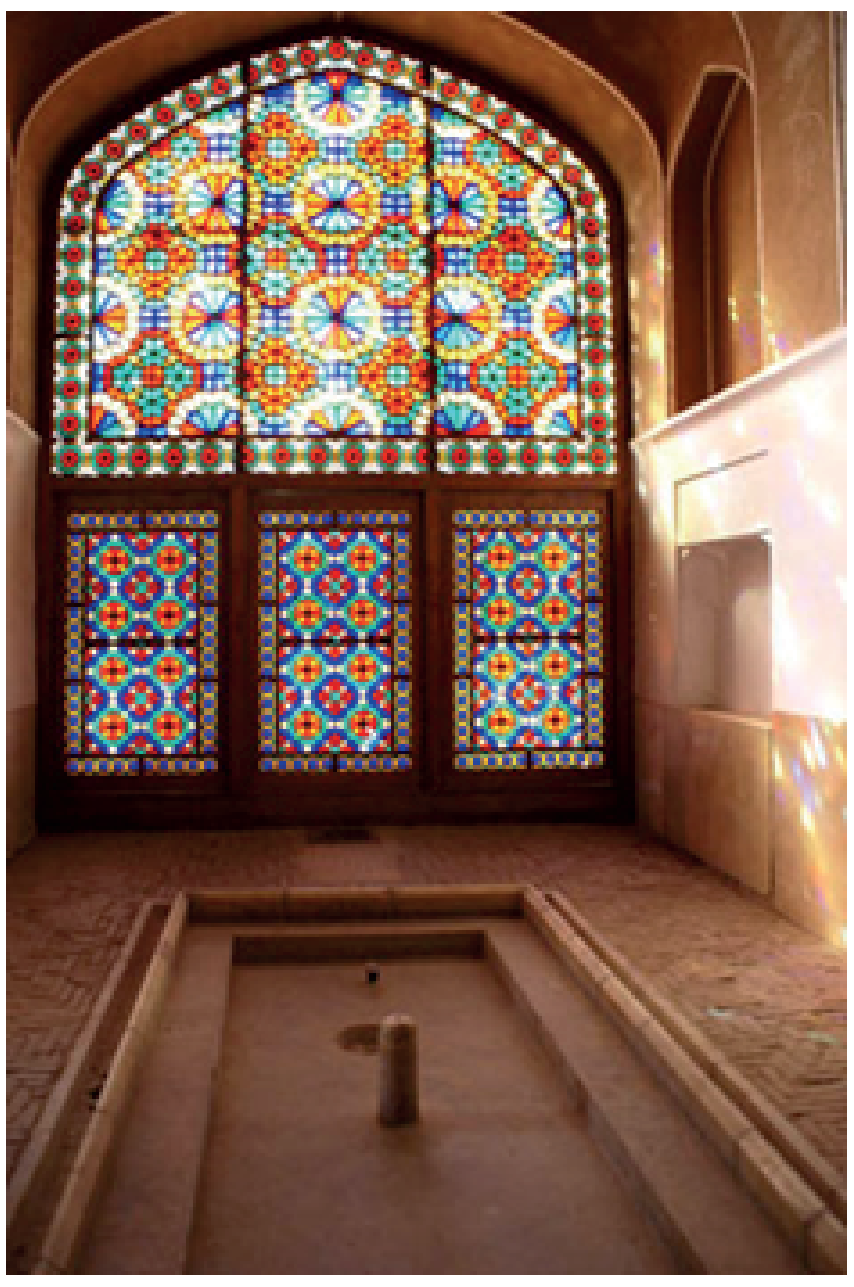

Fig. 3. A Sedari sash window, Dolat Abad Garden of Yazd (Amraei, 2004) 


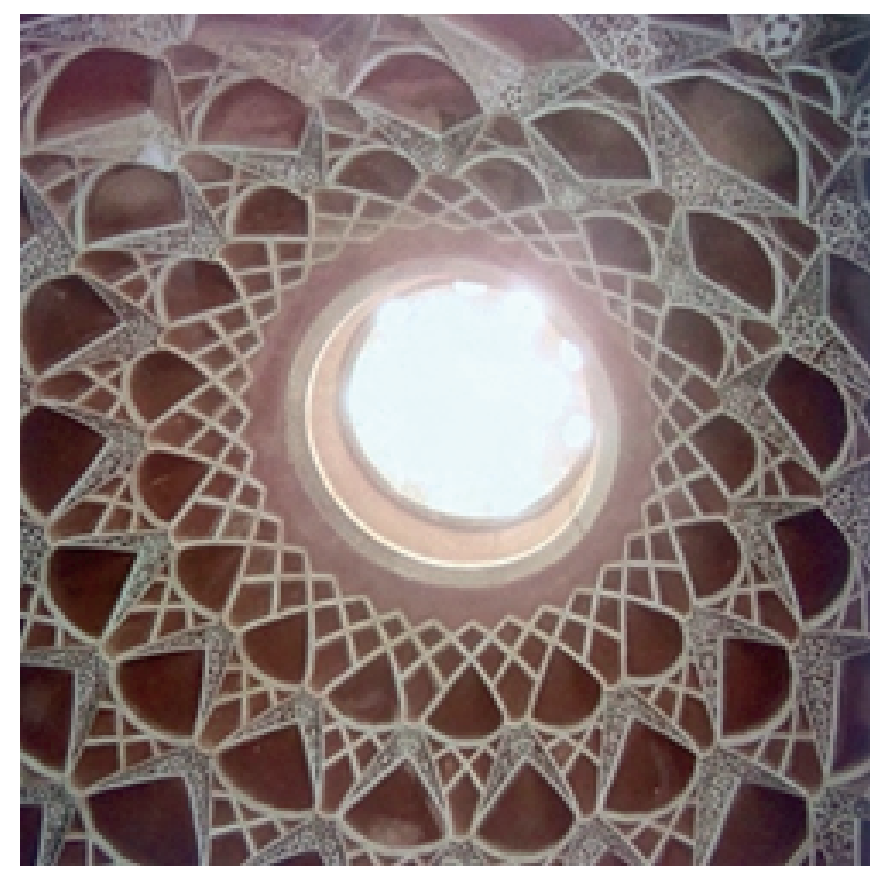

Fig.4. Presence and entrance of light into the building, a view of the historical building of Borujerdi's house in Kashan (Moina al-Sadat Hejazi, 2008).

In the vast majority of traditional houses, the main axis of the building was its north-south axis, and buildings were aligned in the direction of sunlight so that they relished in the warmth of sun in winter and the coolness of shades in hot summer days. The main living spaces were on both sides of the house to the north and south, and areas of lower importance, particularly service areas, were built on eastern and western sides. One advantage of the adjacency and integration of two or more spaces is the possibility of space, perspective and light expansion “[16].

\section{Elements of Lighting in Architecture}

Architectural elements of lighting comprise of two major groups: light controllers and skylights. Undercoats, Sabat (arched structure to provide shade), Shabak (a grid for protection of the interior space), vents, Horno (skylight mounted on ceiling), Roshandan (light outlet in the ceiling) and sash windows are examples of controllers and light windows in traditional Iranian buildings (Figures 5 and 6).

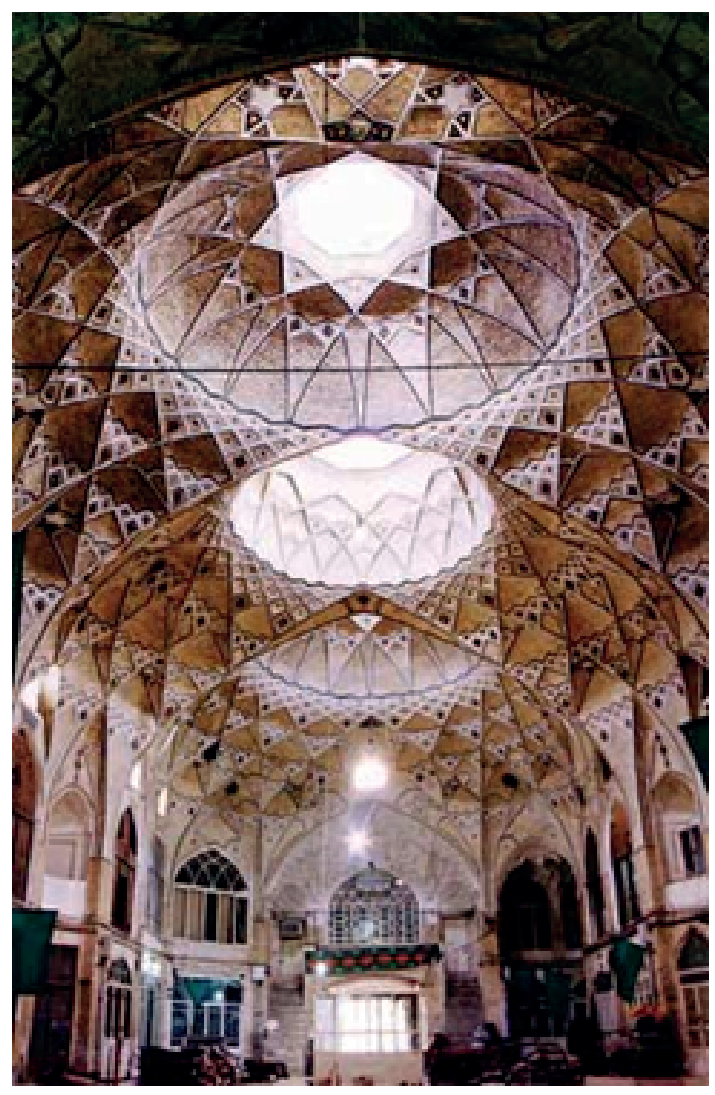

Fig.5. Horno, Tehran's Shoemakers Market, Timcheh Hajib al-Dowleh (Amraei, 2004)

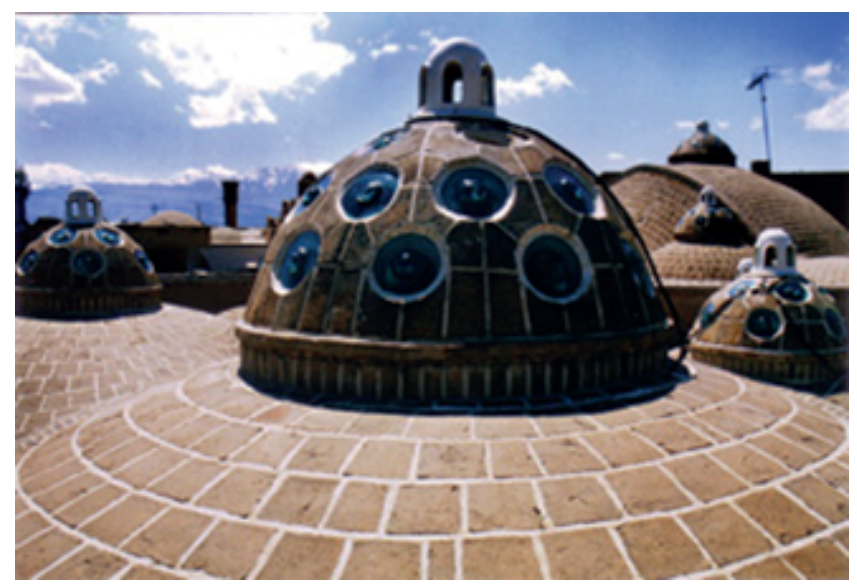

Fig.6. An example of the Jamkhaneh (www.interiordesign.com)

Light is a global intermediary and a key to resolving the mysteries of the world in which we inhabit; the mysteries that dwell in the depths of the present and future of mankind. The natural elements in Iranian architecture has been used in a metaphorical way. 
In traditional architecture and in Islamic culture, light is a symbol of God and divine light. Light is one of the most distinctive aspects of the Iranian architecture and it embodies divine wisdom. The role of light in Islamic architecture is underscored by the principle of manifestation, according to which each location possesses a certain lighting feature. In the architecture of Iranian houses, you cannot enter a building directly as there are several intermediate spaces that are organized in a hierarchical order.

Elements such as Jelokhan (open space before the entrance), portal, vestibule and corridors have been designed for this purpose, which are characterized with a progressive development of lighting. Light plays a fundamental role in the sequence of space, and it is the symbol or sign most comparable to divine unity.

\section{ELEMENTS GENERATING TRANSPA- RENCY IN IRANIAN ARCHITECTURE}

Important factors are involved in appreciating the transparency of buildings in the Islamic period of Iran. According to the abovementioned, the expression of transparency in Iranian architecture can be categorized in obvious transparency and phenomenal transparency, with each having their special instances. In addition to the above, we explore the semantic clarity in Islamic architecture of Iran, which is pivotal to the formation and development of magnificent works of Iranian Islamic architecture.

\section{Transparency Levels}

In Islamic-Iranian architecture, constrained by climatic and cultural factors, emergence of transparency levels has been impeded. In general, openings, with the exception of a few cases, have small dimensions compare to their adjacent space. For example, elements such as doors and windows, and Shabak, Fakhr and Madin sash windows illustrate the transparency of levels.

\section{Reductive Material Transparency (Spatial Transparency):}

The empty space constitutes one of the key means of creating transparency in space. Since transparency is one of the principles of existence, it is only natural that it is a chief criterion in the general course of the architecture as well. The world architecture has historically developed a tendency towards transparency, or in the architectural sense, towards diminishing materials and expanding space. This process, nevertheless, is more palpable in Iranian architecture and the Islamic worldview (which, after the emergence of Islam in Iran, dominates this land based on the belief that that the universe is evolving from a material into a spiritual state), which expedites the movement of architecture towards transparency [14].

The clear example of this decline in materials and the spatial expansion in Iranian architecture was the creation of Gonbad Khaneh (dome house), porch, Soffeh (indoor space) central courtyard, Goshwareh (rooms on both sides of alcoves), vestibules, Jelokhan (space before the entrance) and the small yards, which demonstrate a trajectory of expanded size and shape, alignment of the structure and subsequently spatial expansion in the history of Iranian architecture from the Khorasani to Qajar period.

\section{Phenomenal Transparency}

Phenomenal transparency implies layering and spatial ambiguity, as observed in Islamic architecture of Iran. In fact, the Islamic architecture is founded upon layered design and, in many cases, the observer is able to locate its position in space by means of various space-specific situations. Spatial transparency in Iranian architecture refers to the inclusion of one or more spatial states in a spatial unit. Each spatial state embraces several senses, which besides preserving its spatial independence, exhibits the desire and tendency for integration with other spaces 
[17]. The spatial states of the Iranian architecture are to offer the experience of an intimate, personal and private spaces alongside glorious and magnificent spaces, and provide a blending of closed, semi-open and open spaces, insofar as you feel as though your soul has taken shelter or a special opening has been accomplished.

"This type of architecture, with heavy dependence on the continuity of positive space, does not forge any disconnection or impediment in the path of human movement. You find yourself incessantly moving in a wavy and opening space that seems to remain integrated perpetually “‘[18].

In the book "Isfahan, the image of Paradise", Styrellen points to this characteristic of Iranian architecture, arguing that spatial integration is a fundamental aspect of Iranian architecture. In the next section, we discuss a type of transparency that is concerned with symbolic and sacred concepts in Iranian Islamic art, and has exerted a huge influence on Iranian architectural interpretation.

\section{Semantic Transparency:}

Semantic transparency in Islamic architecture represents a type of transparency that induce transformations in the mind of the observer, which is more pertained to the spiritual rather than physical coordinates of the observer. In this way, it imparts the transcendental and sacred meaning of the Islamic to the mind of the observer and the user of the structure, which emanates from the feeling of the presence and understanding the atmosphere the epitome of which can be found in the Islamic architecture of Iran.

Titus Burckhardt contends that, based on the spiritual perspective on the world, the beauty of an entity is the same as the transparency of its existential and material cover. In other words, they consider transparency as the expansion of vision and since the highest human sight is his spiritual and inner vision, transparency allows going beyond the ostensible appearance of a work into its inner meaning and content or the manifestation of the kingdom of heavens in the material existence ${ }^{[20]}$. For example, water and at a lower level, mirrors and even tiles, with a glossy and shiny surface, reflect the light and convey a particular sense of silence and spatial and spiritual calmness in the observer. According to Sayed Hussein Nasr, divine light reveals geometric clarity and rational transparency, leading man towards the God. In general, forging an empty space in a spiritual setting conveys a sense of silence and purity to the observer to objectify the notion of human returning to inner self and forging a relationship with the Creator.

\section{CONCLUSION}

In the Islamic-Iranian art and culture of Iran, colors have been stratified into categories such as the most valuable, most noble, most beautiful and most elated, among other things. The golden domes, the abundant use of blue backgrounds and white motifs and the sacred and holy attributes attached to green offer support to this proposition. The natural elements in Iranian architecture has been primarily used in a metaphorical sense. Distinction of colors, which is rooted in the divine wisdom, enables man to appreciate the beauty and recognize the dimensions of the universe. In traditional architecture and in Islamic culture, light is a symbol of God and divine light.

Light is one of the most distinctive aspects of Iranian architecture and an element of divine wisdom. The role of light in Islamic architecture embodies a special stress on the principle of manifestation. That is, each site or place possesses a special light to which it 
belongs. The study of works and theories of Iranian Islamic architecture suggest that transparency, in addition to the visual and phenomenal dimension, has a semantic dimension. That is, in some cases, transparency of surfaces in form of sash windows has been used to forge a visual connection between interior and exterior spaces.

Also, the advancement of technology, and advent of modern covering techniques have resulted in the expansion of the interior space and the refinement of structural mass, but these have not been the main objective so that with the development of Islamic architecture, attempts have been made to foster complexity and ambiguity, rather than transparency, by nurturing different spatial interpretations through a layered design, which contributes to phenomenal transparency.

The Iranian architectw, driven by phenomenal transparency, have not been in search of creating complexity, attractiveness and spatial diversity from a purely architectural perspective. Instead, they have pursued cultural and transcendental goals, the most important of which are respect for privacy, hierarchy, and representation of religious and sacred concepts that are epitomized in the structure of mosques.

In addition, the most important feature of Islamic architecture of Iran is that, while fulfilling climatic and functional demands, it lays the foundation for man's journey from outer to inner state, from shape to meaning, and from creation to kingdom of heavens.

In conclusion, it can be asserted that the architect, as an artist, wraps the truth in a material cover to turn it into a path of ascendance for man. As a result, one can achieve semantic transparency by upgrading his existential capacity, and architecture, as the container of human capacity, is vital to this process.

\section{REFERENCES}

1. Corben, Henry, (2001). The Illuminated Man in Iranian Sufism, Translated by Faramarz Javaherinia, Vol. I, Golban.

2. Afshar, Iraj, (1999), Color Types in Persian Language, Linguistics Journal, $14(1 \& 2)$.

3. Mansoori, Mehrzad, (1996), Study of the color terms in Farsi language, Journal of Linguistics, 13 $(1 \& 2)$

4. Ghazaei, Muhammad, (1997), Sensory perception from the viewpoint of Ibn Sina, Printing Islamic Propagation Office of the Qom Seminary.

5. Sharif Mahallati, Moayed, (1958), Seven in the world culture, Shiraz.

6. Ahmadi Maleki, Rahman, (1999), Colored Figures in Haft Peykar. Fiction Literature Quarterly, 8 (52).

7. Ibn Rastah, Ahmad, (1986), Al-Alaq Al-Anfiseh, Translated by Hossein Gharchanlou, Amir Kabir Publications.

8. Sajjadi, Mohammad Ali, (1990), Righteous cloak and cloak of Sufism. (First Edition) Elmi Farhangi Publication

9. Qiyabkelou, Zahra, (2012), Basics of building pPhysics 3, Electrical Lighting, Amir Kabir University of Technology, Jahad Daneshgahi Publication, First Edition.

10. Forty, A. (2004). Transparency, The disconnecting concept in architecture, words and buildings. London: Thaes \& Hudson ltd.

11. Dehkhoda, Mohammad Taghi, (2007), Dehkhoda Dictionary, Tehran, University of Tehran.

12. Giedion, Sigfroud. (1962). Space, time, and architecture. Cambridge Press.

13. Suhrawardi, Sheikh Shahabodin Yahya, (1998), Hikma al-Ashraq, Translated by Seyed Jafar Sajjadi, Tehran University Press, Tehran.

14. Mirmiran, Syedadi, (1998), Transition from material to spirit, Architecture and Urbanization, No. 42: 100-94.

15. Ascher barnstone, D. (2003). Transparency: a brief introduction. Journal of Architectural Education 56

16. Tabatabai, Zahra and Zahra Abbasi, (2016), Semantic analysis of visual effects of light in the interaction between Khalidah's wisdom and 
Iranian architecture and urbanism, Journal of Urban Management, No. 42, 106-87.

17. Haeri Mazandarani, Mohammad Reza, (2009) The role of space in Iranian architecture, Tehran: Office of Cultural Research.

18. Ardalan, Nader and Laleh Bakhtiar, (2012), Sense of harmony (the role of tradition in Persian Architecture), translated by Hamid Shahrokh. Isfahan: Khak.

19. Styrene, Henry, (1998), Isfahan, the image of Paradise, translated by Jamshid Arjomand. Tehran: Farzane Rouz Publication.

20.Burckhardt, Titus, (1990) Holy art, principles and methods, translated by Jalal Sattari. Tehran: Soroush. 